\title{
O DOCUMENTO FOTOGRÁFICO: UM OBJETO SOCIAL E DE COMUNICAÇÃo PARA A GERAÇÃo dE CONHECIMENTO
}

\author{
THE PHOTOGRAPHIC DOCUMENT: A SOCIAL AND COMMUNICATION \\ OBJECT FOR THE GENERATION OF KNOWLEDGE
}

EL DOCUMENTO FOTOGRÁFICO: UN OBJETO SOCIAL Y DE COMUNICACIÓN

PARA LA GENERACIÓN DE CONOCIMIENTO

Joana Sousa Rodrigues ${ }^{1}$

${ }^{1}$ Universidade do Porto

Correspondência

'Joana Sousa Rodrigues

Universidade do Porto

Porto, PT

E-mail: joanasousarodrigues.14@gmail.com

\section{(c) (7)}

JITA: IC. Index languages, processes and schemes.

Submetido em: $05 / 03 / 2018$

Aceito em: 23/04/2018

Publicado em: 27/08/2018 
RESUMO: O documento fotográfico constitui um enorme desafio para aquela que é chamada de Era de Informação e que vem alinhada com o avanço tecnológico, nomeadamente a imposição do digital, através de dispositivos de captura de imagem. O tratamento de informação fotográfica, embora, à primeira vista, espelhe um leque imenso de oportunidades e benefícios, ainda padece de um estudo limitado e pouco desenvolvido. Se por um lado, os documentos de caráter textual estão presentes, em esmagadora maioria, nos centros de informação e, por esse motivo, o sua análise e tratamento são realizadas quotidianamente, por outro, a imagem tem vindo a posicionar-se, ainda que lentamente, na sociedade de informação como um meio implacável na geração de conhecimento. A imagem é dominante na comunicação, mas a fotografia tem ainda um tratamento diverso, no que toca à descrição, interpretação e uso sistemático. A dificuldade de pesquisa em coleções de imagens é conhecida e evidente.Partindo de um estudo de caso com investigadores produtores de imagem, pretende-se perceber de que forma a fotografia pode constituir um benefício, entendendo como esta deve ser tratada de modo a que se torne um recurso de valor, com efeitos significativos na recuperação da informação. Este estudo assenta, sobretudo, nas tarefas de descrição necessárias para dar o contexto ao documento fotográfico, pois esta é uma atividade fundamental para que estes sejam interpretáveis e recuperáveis. O processo de interação com os investigadores constitui o processo metodológico fundamental do trabalho, pois permite tornar os modelos de descrição da imagem dinâmicos e flexíveis, permitindo que esta não seja limitada a determinados domínios.

PALAVRAS-CHAVE: Ciência da informação. Documento fotográfico. Sociedade da informação. Tratamento de informação

ABSTRACT: The photographic document constitutes a huge challenge for what is called the Information Age and is aligned with the technological advance, namely the imposition of digital, through image capture devices. The treatment of photographic information, although at first glance, shows an immense range of opportunities and benefits, still suffers from a limited and underdeveloped study. If, on the one hand, textual documents are present, in an overwhelming majority, in the information centers and, for that reason, their analysis and treatment are carried out daily, on the other, the image has been positioning, even though slowly, in the information society as a relentless medium in the generation of knowledge. The image is dominant in the communication, but the photograph still has a diverse treatment, as far as the description, interpretation and systematic use. The difficulty of searching in collections of images is well known and evident.

Starting from a case study with image-producing researchers, it is intended to understand how photography can be a benefit, understanding how it should be treated so that it becomes a resource of value, with significant effects on information retrieval. This study is based, above all, on the descriptive tasks necessary to give the context to the photographic document, since this is a fundamental activity for them to be interpretable and recoverable. The process of interacting with the researchers constitutes the fundamental methodological process of the work, since it allows to make the models of description of the image dynamic and flexible, allowing that it is not limited to certain domains.

KEYWORDS: Information processing. Information science. Information society. Photographic document.

RESUMEN: El documento fotográfico constituye un enorme desafío para aquella que se llama la Era de Información y que viene alineada con el avance tecnológico, en particular la imposición de lo digital, a través de dispositivos de captura de imagen. El tratamiento de información fotográfica, aunque, a primera vista, refleja un abanico enorme de oportunidades y beneficios, aún padece un estudio limitado y poco desarrollado. Si por un lado, los documentos de carácter textual están presentes, en aplastante mayoría, en los centros de información y, por ese motivo, su análisis y tratamiento se realiza cotidianamente, por otro, la imagen se ha ido posicionando, aunque, lentamente, en la sociedad de la información como un medio implacable en la generación de conocimiento. La imagen es dominante en la comunicación, pero la fotografía todavía tiene un tratamiento diverso, en lo que se refiere a la descripción, interpretación y uso sistemático. La dificultad de búsqueda en colecciones de imágenes es conocida y evidente. A partir de un estudio de caso con investigadores productores de imagen, se pretende percibir de qué forma la fotografía puede constituir un beneficio, entendiendo cómo ésta debe ser tratada de modo que se convierta en un recurso de valor, con efectos significativos en la recuperación de la información . Este estudio se basa, sobre todo, en las tareas de descripción necesarias para dar el contexto al documento fotográfico, pues ésta es una actividad fundamental para que éstos sean interpretables y recuperables. El proceso de interacción con los investigadores constituye el proceso metodológico fundamental del trabajo, pues permite hacer que los modelos de descripción de la imagen dinámicos y flexibles, permitiendo que ésta no se limite a determinados ámbitos.

PALABRAS Clave: Ciencia de la información. Documento fotográfico. Sociedad de la información. Tratamiento de la información 


\section{INTRODUÇÃ̃o}

Convicta da importância da imagem para a Ciência da Informação (CI), surge este artigo que tem com intuito sensibilizar os demais para a necessidade de contrariar a banalização que o documento fotográfico tem vindo a sofrer, não só pela facilidade como, atualmente, está ao alcance de qualquer um, através de dispositivos móveis, de digitalização e de impressão, mas também pela forma redutora como ainda é vista no contexto da CI.

A sociedade de informação tende a ser a impulsionadora da mudança e do avanço, quer pelas necessidades que ambiciona serem saciadas, quer pela vontade de vislumbrar novas tendências. E é de tendências que se fala. $\mathrm{O}$ documento fotográfico alberga em si inúmeras possibilidades e tendências. Se na sua gênese já encontramos um valor incalculável no que toca à preservação da memória e à promoção da nostalgia (pelo conteúdo que dispõe), hoje, a fotografia, tende a apontar para novas metas e propor novos desafios, seja através da sua eficiente conservação, seja através das técnicas e metodologias que devem ser utilizadas para a sua conveniente descrição nos mais diversos sistemas de informação.

O artigo aponta para a consciencialização do documento fotográfico como um objeto social e de comunicação, mostrando evidências deste facto e relembrando o seu papel na geração de conhecimento para a sociedade de informação e os seus intervenientes. Além disso, o artigo posiciona o documento fotográfico no processo documental, facto importante, visto que a tipologia documental que maioritariamente é abraçada por este processo está confinada aos documentos de caráter textual, ideia que deve ser desmistificada e contornada, no sentido de uniformizar todas as tipologias documentais. Afinal falamos de tratamento de informação, apenas de tratamento de informação. Valerá a pena rotular, escalar ou hierarquizar a informação mediante o seu suporte ou linguagem?

É a interpretação que fazemos e as abordagens que utilizamos para o tratamento de informação que definem um resultado, portanto esqueçamos as medidas de importâncias e as pirâmides de categorização e centremo-nos na Ciência da Informação tal e qual como ela deve ser vista.

Neste trabalho a componente de avaliação prende-se num estudo de caso com investigadores produtores de fotografia nos seus projetos de investigação. Este será o fio condutor para perceber o comportamento informacional daqueles que lidam com a fotografia mas, sobretudo, para detetar as técnicas que devem ser privilegiadas quando falamos de descrição imagética. 


\section{REVISÃO DE LITERATURA}

O caráter científico atribuído ao documento fotográfico é inquestionável, pois este permite confirmar o real e alcançar a veracidade sobre algo, além disso o seu papel na liberdade de expressão e no respeito pela linguagem visual é imenso. Segundo Roland Barthes (2012), o documento fotográfico garante a diversidade na comunicação e, por isso, a sua posição numa sociedade de informação, dotada de mecanismos de expressão tão vincados, não pode ser desprezada. Também Serén (2013) vê o documento fotográfico como um objeto social integrante de uma sociedade de informação e comunicação, pois possui capacidade de registo, através das anotações das transações da sociedade transversal e global.

Se dúvidas existissem sobre a constituição do documento fotográfico como um objeto social, vejamos os elementos básicos que este possui e que são características fundamentais para adquirir este estatuto. Em primeiro lugar, o documento fotográfico possui uma intenção, diretamente ligada à vontade e ao propósito; em segundo detém uma expressão, que em tudo se relacionada com a maneira de exteriorizar uma ideia, de transmitir uma noção ou parecer; em terceiro tem uma inscrição que é fundamental para manter os dois elementos anteriores.

\section{IMAGEM: EMISSOR - - - RECEPTOR}

$\longrightarrow$ MEDIAÇÃO: LINGUAGEM FOTOGRÁFICA

Figura 1. Linguagem Fotográfica

Fonte: Boccato e Fujita (2006)

O documento fotográfico, como meio de comunicação que é, tem assumido um papel decisivo para as reflexões no domínio do conhecimento científico. A sua particularidade social, ainda muito associada aos media, revolucionou as ditas Artes Visuais, pois alberga em si estruturas de interoperabilidade entre sistemas humanos, sociais e digitais.

A fotografia não é mais vista apenas como uma forma de promover a memória e a nostalgia, ela comporta um conjunto de dimensões, através dos novos meios de informação e comunicação, que lhe conferem a capacidade de disseminar informação. A fotografia já não é apenas o produto de um momento captado, é sim fruto de um conjunto de elementos que a distinguem e que permitem a sua interpretação, é informação agregada e disposta num suporte, a fotografia «é universal, mas sempre particularizada» (SIMIONATO; NETO; SANTOS, 2015, p.59). No que toca à produção noticiosa, também o documento fotográfico já começa a ser visto como uma estratégia de comunicação importante, pois se um jornalista 
utiliza uma fotografia numa notícia não é porque esta vai ocupar um espaço vazio, mas porque esta desempenha um papel de difusão de informação tão eficaz como o texto.

O processo documental, no parágrafo acima abordado, e que vai resultar na representação e recuperação da informação fotográfica, alicerça-se em três fases, começando pela análise do conteúdo o documento, seguindo-se a síntese do conteúdo analisado e terminando com a representação do conteúdo do documento. Na verdade, estamos a esmiuçar as questões que assentam no documento fotográfico, contudo estas três fases de análise de documentos são iguais, trata-se de documentos de caráter textual ou imagético.

Que o tratamento da informação deve ser consistente e normalizado sejam quais forem as suas tipologias documentais, não há dúvida, todavia a interpretação que é realizada a um documento de caráter textual e a um documento de caráter imagético é, inevitavelmente, diferente. A verdade é que um texto é capaz de fornecer ao seu leitor um conjunto de pormenores que, à partida, serão mais fáceis de apreender. Um texto permite uma leitura mais célere, pois permite que o leitor perceba intuitivamente os assuntos e detalhes, sem que tenha que fazer leituras mais complexas e fora do que é apresentado. Já as imagens, em particular os documentos fotográficos, incutem aos seus leitores uma interpretação mais atenta, pois estes necessitam de ponderar com minúcia todos os pormenores para entender com clareza a mensagem daquele documento. Um texto, a priori, será menos dúbio e direto, a fotografia pode induzir em desvios e pouco aprofundamento da matéria tratada e é por esse motivo que, por diversas vezes, a fotografia serve de complemento a um texto. Na verdade, um texto diz, mas a fotografia prova o que foi relatado.

A abordagem no parágrafo acima descrita permite provar a relevância da inserção do documento fotográfico no processo documental, pois só o tratamento de informação destes documentos, nomeadamente a descrição, pode eliminar as falhas interpretativas do documento fotográfico, uma vez que um complemento de descrição coeso, unilateral e fiel à mensagem poderá dar os detalhes mais do que suficientes para que o leitor perceba a imagem, a interprete e apreenda a sua lição.

As imagens abaixo apresentadas (imagens 2 e 3) esboçam um exemplo do que anteriormente foi descrito. A imagem 3 apenas permite uma leitura visual, pois trata-se de uma fotografia e a imagem 4 apenas permite uma leitura textual, pois trata-se de uma notícia. Ambas as imagens relatam o mesmo acontecimento, porém a imagem 4 permite ao leitor adquirir mais pormenores que a imagem 3, devido às características intrínsecas a esta tipologia documental. Este é um caso em que o complemento de uma fotografia a um texto é essencial como prova de um facto, no entanto, ambas poderiam surgir distintamente se a imagem 3 tivesse uma descrição a si associada e que permitisse ao leitor fazer uma leitura concreta e imediata sem ter que recorrer a material textual. 


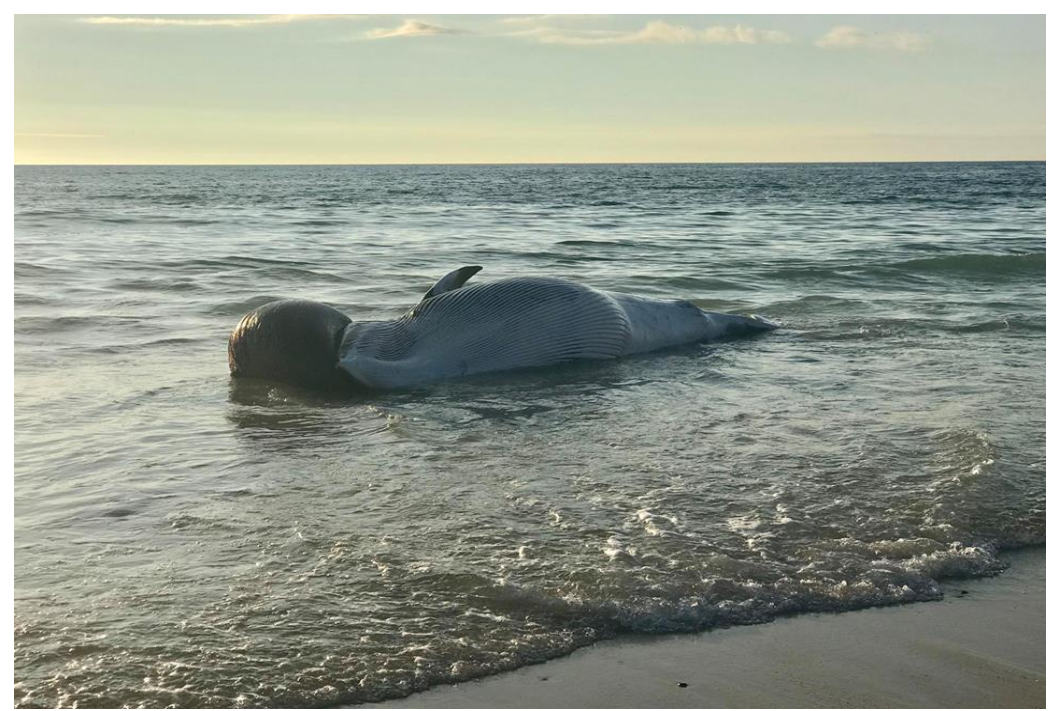

Figura 2. Fotografia sobre notícia «Baleia morta dá à costa no Furadouro» Fonte: Jornal de Notícias - Portugal (2017)

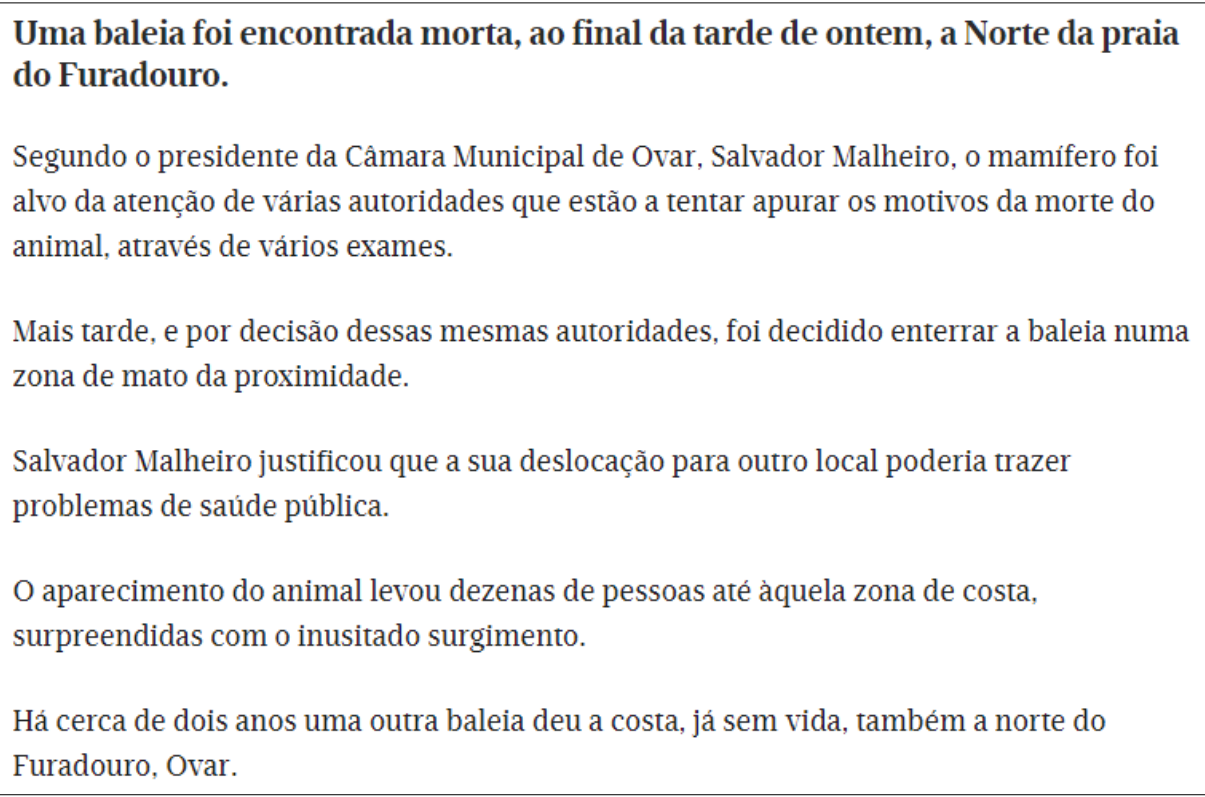

Figura 3. Notícia «Baleia morta dá à costa no Furadouro» Fonte: Jornal de Notícias - Portugal (2017)

Segundo Boccato e Fujita (2006) «a análise documental é um processo instrumental»e é por esse motivo que a Ciência da Informação, através do seu caráter «multidisciplinar pósmoderna», deve estimular a definição de orientações que levem ao acesso competente de imagens nos sistemas e nas unidades de informação. É nesta sequência de ideias que figura o profissional de informação que vai «representar o conteúdo da imagem fotográfica para torná-la acessível - socialização do conhecimento - ao usuário». Desta forma, o profissional

\begin{tabular}{|c|c|c|c|c|c|}
\hline (C) RDBCI: Rev. Digit. Bibliotecon. Cienc. Inf. & Campinas, SP & v.16 & n. 3 & p. 373-386 & set./dez. 2018 \\
\hline
\end{tabular}


de informação tem o intento de procurar e obter as informações que satisfazem as necessidades de pesquisa, bem como criar serviços de referência que sejam aptos à concretização das tarefas a que se propõe.

Num outro ponto de vista é possível discutir sobre como a utilização de imagens tem um efeito de recordação significativo no cérebro humano que estabelece, mais rapidamente, ligações entre os objetos e os seus contextos, potenciando um entendimento mais célere e eficiente.

Silva (2014) aborda a forma como a fotografia pode desencadear o fenómeno «verconhecer», afirmando que esta tem características que lhe permitem desempenhar ações cerebrais de memória e reconhecimento únicas. A provar esta tese existem os estudos de Czerwinski e Horvitz (2002) e de Elsweiler, Ruthven e Jones (2005) que afirmam que o ser humano esquece muitos detalhes das tarefas que desempenha poucos meses após as ter concluído. Todavia, com o primeiro estudo, afirma-se que quando confrontados com imagens ou vídeos tendem a recordar mais prontamente o esquecido e, no segundo estudo, que com o auxílio de anotações recordam facilmente o que já não era lembrado.

\section{MATERIAL E MÉTODOS}

As abordagens e metodologias selecionadas para dada investigação são alguns dos pilares fundamentais para o sucesso e equilíbrio da mesma, uma vez que são o trajeto que é necessário assumir e realizar para alcançar o conhecimento científico capaz de chegar a um resultado. Os métodos de trabalho são os mecanismos, procedimentos e as ferramentas essenciais no trabalho de investigação. Além disso, estes possibilitam que sejam descobertos os fundamentos teóricos que estão por trás dos métodos, influenciando, assim, a tomada de decisão do investigador.

Para esta investigação a metodologia utilizada será o método qualitativo de investigação, através do estudo de caso, nomeadamente a pesquisa exploratória. A pesquisa exploratória tem o intuito de melhorar a familiarização do investigador com o caso em estudo, assim, este método servirá para que seja feita uma investigação preliminar sobre os temas a abordar, para que seja possível refletir sobre estes e melhorar a sua compreensão. $\mathrm{O}$ tratamento de informação fotográfica e o posicionamento da tipologia documental a si associada na sociedade de informação ainda não é vastamente estudado, por isso, com a pesquisa exploratória pretende-se que sejam geradas ideias e hipóteses que complementem este tema e que auxiliam o trabalho a desenvolver, seja na recolha da bibliografia a recolher, nas ideias a adotar ou nos pressupostos a gerar.

O estudo de caso é parte integrante do método qualitativo de investigação, que tem o objetivo de analisar especificamente o tema em questão e, dessa maneira, criar esclarecimento profundo sobre este. Para este estudo selecionou-se um conjunto de cinco

\begin{tabular}{l|l|l|l|l|l} 
(C) RDBCI: Rev. Digit. Bibliotecon. Cienc. Inf. & Campinas, SP & v.16 & n.3 & p. 373-386 & set./dez. 2018 \\
\hline
\end{tabular}


investigadores com vínculo à Universidade do Porto, de diferentes domínios, nomeadamente saúde cardiovascular, bem estar animal, smart cities, jornalismo de investigação e biodiversidade. Estes investigadores foram selecionados pelo facto de serem produtores de fotografias nos seus projetos de investigação, além disso, quando confrontados com a possibilidade de participarem neste estudo, estes cinco foram aqueles que mais deram importâncias às questões de descrição de imagem e que consideravam que essa era uma lacuna evidente no processo que desenvolvem no decurso dos seus projetos.

A Figura 4 evidencia a abordagem metodológica efetuada, desde o contacto com os investigadores até à tarefa de avaliação de resultados. A análise a esta abordagem será retomada posteriormente.

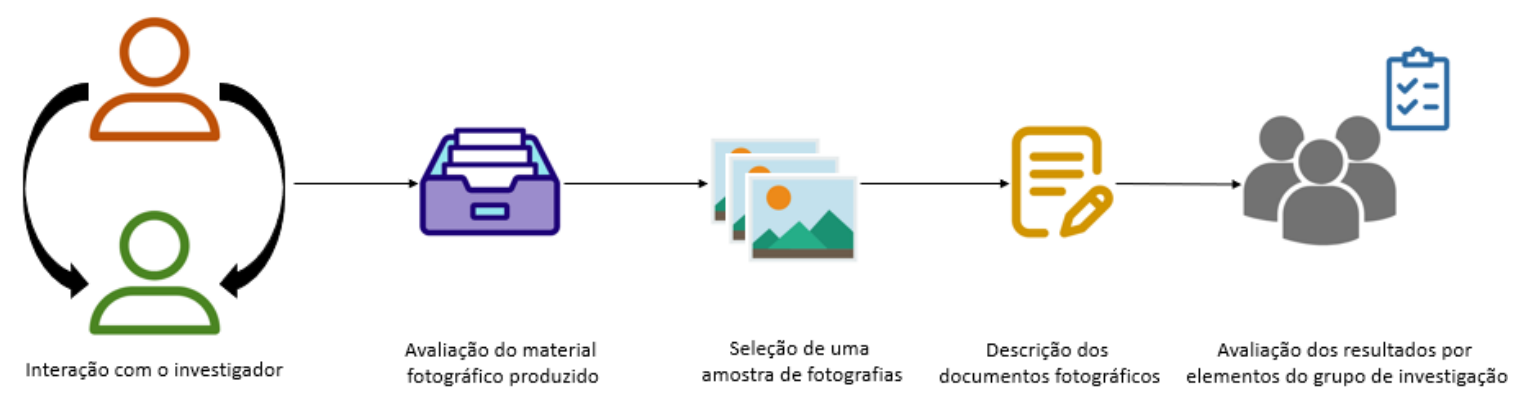

Figura 4. Abordagem metodológica

Fonte: Autoria própria

\section{RESULTADOS E DISCUSSÃo}

A análise documental, inserida no processo documental, requer especificações, nomeadamente a utilização de uma linguagem controlada para a descrição dos documentos fotográficos. O uso de linguagem controlada está inerente ao controlo terminológico, à utilização de léxico especializado, à representação estreita e fiel do conteúdo do documento, o aproveitamento de relações semânticas e o registo de formas padronizadas de ponto de acesso. Só seguindo estas diretrizes no momento da descrição do documento é que a recuperação vai ser eficiente e corresponder às expetativas do utilizador do sistema de informação, no momento da pesquisa. A utilização de linguagem controlada fomenta precisão nas pesquisas, bem como uma navegação mais eficaz, fornece aos utilizadores um resultado equivalente ao esperado, potencia a anulação de variação de resultados, potencia que o conteúdo recuperável seja muito mais que uma mera descrição do documento e proporciona um ambiente mais dinâmico e executivo.

Para o estudo em questão questionaram-se cinco investigadores sobre o uso da fotografia nos seus projetos. Todos consideraram que a fotografia era essencial na medida em que permitia recolher, com exatidão, pormenores que nenhum outro tipo de anotação textual conseguiria. Contudo, também em unanimidade entre os investigadores, está o facto de esta 
tipologia documental carecer de uma componente de descrição que lhes confira um valor acrescido.

$\mathrm{Na}$ reunião preliminar realizada com os investigadores foram selecionados vários momentos nos quais a descrição das suas fotografias poderia ser útil, todavia, as seguintes quatro ocorrências foram aquelas que surgiram na maioria dos discursos dos investigadores.

1) Permite que não sejam esquecidos pormenores relevantes em relação à fotografia e ao momento em que foi tirada. Vários investigadores referiram que os seus projetos são de longa duração e, por vezes, o facto de as suas fotografias não serem descritas no momento da sua recolha, desencadeia que, mais tarde, determinados detalhes sejam esquecidos.

2) Permite que as fotografias sejam mais prontamente recuperadas dentro dos sistemas que utilizam para armazenar e organizar as suas fotografias. Consideram que através de, por exemplo, termos de indexação ou metadados, as fotografias seriam mais facilmente recuperadas.

3) Permite que outros investigadores dentro do projeto e pessoas externas a este, que tenham interesse nos materiais produzidos, consigam interpretar devidamente as fotografias, sem desvios nem dúvidas.

4) Permite que as seja potenciada a reutilização das fotografias. Parte dos investigadores, no final dos seus projetos, publicam os seus dados e restantes materiais em repositórios, blogs, no site do projeto ou mesmo em sites disciplinares e, por isso, esperam que as suas partilhas fomentem a visualização e reutilização. Com o complemento da descrição os investigadores esperam ver as suas fotografias reutilizadas por outros, seja porque a descrição evidencia cautela e precisão durante o processo de recolha destes documentos, seja porque, desta forma, é garantida a conformidade entre o que se vê e o que se lê.

Depois da reunião preliminar foi necessário selecionar, junto dos investigadores, o conjunto de fotografias que iriam constituir a amostra a estudar. Cada investigador selecionou 4 fotografias, o que constitui uma amostra final de 20 fotografias.

Posteriormente a esta tarefa partiu-se para a descrição das fotografias, tarefa esta que ficou ao total encargo dos investigadores. Para facilitar este trabalho foi feita uma navegação com os investigadores por diversas fontes de informação que utilizam termos de indexação e metadados para descrever os seus recursos. Entre estas fontes de informação estiveram catálogos académicos, plataformas de gestão de recursos de centros noticiosos, repositórios temáticos e institucionais e algumas ontologias disponíveis online.

Como seria de esperar, dado a diversidade de domínios de investigação, o vocabulário utilizado foi diversificado. Contudo apresentavam pontos de concordância. A Tabela 1 evidencia, de forma generalizada, o trabalho de descrição desenvolvido pelos investigadores. 
Tabela 1. Classificação do vocabulário utlizado para a descrição fotográfica

\begin{tabular}{|c|c|c|c|c|}
\hline & Fotografia 1 & Fotografia 2 & Fotografia 3 & Fotografia 4 \\
\hline Investigador 1 & $\begin{array}{l}1 \text { temporal; } \\
1 \text { espacial; } \\
4 \text { semânticos; } \\
4 \text { administrativos; } \\
1 \text { técnico; } \\
2 \text { descritivos. }\end{array}$ & $\begin{array}{l}1 \text { temporal; } \\
1 \text { espacial; } \\
2 \text { semânticos; } \\
4 \text { administrativos; } \\
1 \text { técnico; } \\
3 \text { descritivos. }\end{array}$ & $\begin{array}{l}1 \text { temporal; } \\
5 \text { espaciais; } \\
3 \text { semânticos; } \\
4 \text { administrativos; } \\
1 \text { técnico; } \\
2 \text { descritivos; } \\
1 \text { genérico. }\end{array}$ & $\begin{array}{l}1 \text { temporal; } \\
1 \text { espacial; } \\
2 \text { semânticos; } \\
4 \text { administrativos; } \\
1 \text { técnico; } \\
2 \text { descritivos. }\end{array}$ \\
\hline Investigador 2 & $\begin{array}{l}2 \text { temporal; } \\
2 \text { espacial; } \\
2 \text { administrativos; } \\
2 \text { técnico; } \\
5 \text { descritivos; } \\
2 \text { genéricos. }\end{array}$ & $\begin{array}{l}1 \text { temporal; } \\
1 \text { espacial; } \\
2 \text { administrativos; } \\
4 \text { descritivos; } \\
2 \text { contexto. }\end{array}$ & $\begin{array}{l}2 \text { temporal; } \\
1 \text { espacial; } \\
2 \text { administrativos; } \\
2 \text { identidade; } \\
5 \text { descritivos; }\end{array}$ & $\begin{array}{l}2 \text { temporal; } \\
2 \text { espacial; } \\
2 \text { administrativos; } \\
7 \text { descritivos; } \\
1 \text { semântico. }\end{array}$ \\
\hline Investigador 3 & $\begin{array}{l}1 \text { temporal; } \\
1 \text { espacial; } \\
4 \text { administrativos; } \\
5 \text { semânticos } \\
2 \text { genéricos; } \\
1 \text { identudade. }\end{array}$ & $\begin{array}{l}1 \text { temporal; } \\
2 \text { espacial; } \\
4 \text { administrativos; } \\
1 \text { técnico; } \\
4 \text { descritivos; } \\
1 \text { genéricos; } \\
1 \text { contexto. }\end{array}$ & $\begin{array}{l}1 \text { temporal; } \\
3 \text { espacial; } \\
1 \text { administrativo; } \\
1 \text { técnico; } \\
5 \text { contexto; } \\
2 \text { genéricos; } \\
2 \text { semânticos. }\end{array}$ & $\begin{array}{l}2 \text { temporal; } \\
1 \text { espacial; } \\
2 \text { administrativos; } \\
1 \text { técnico; } \\
2 \text { genéricos; } \\
7 \text { contexto; } \\
1 \text { identidade. }\end{array}$ \\
\hline Investigador 4 & $\begin{array}{l}1 \text { temporal; } \\
1 \text { espaciais; } \\
3 \text { administrativos; } \\
1 \text { técnico; } \\
3 \text { semânticos; } \\
3 \text { descritivos; } \\
1 \text { genérico; } \\
1 \text { contexto. }\end{array}$ & $\begin{array}{l}1 \text { temporal; } \\
1 \text { espaciais; } \\
2 \text { administrativos; } \\
1 \text { técnico; } \\
5 \text { descritivos; } \\
1 \text { genérico; } \\
2 \text { contexto. }\end{array}$ & $\begin{array}{l}1 \text { temporal; } \\
2 \text { espaciais; } \\
3 \text { administrativos; } \\
2 \text { técnico; } \\
1 \text { semânticos; } \\
2 \text { genéricos; } \\
1 \text { contexto; } \\
1 \text { identidade. }\end{array}$ & $\begin{array}{l}1 \text { temporal; } \\
2 \text { espaciais; } \\
4 \text { administrativos; } \\
2 \text { descritivos; } \\
1 \text { genérico; } \\
4 \text { contexto. }\end{array}$ \\
\hline Investigador 5 & $\begin{array}{l}1 \text { temporal; } \\
1 \text { espaciais; } \\
4 \text { administrativos; } \\
2 \text { técnico; } \\
3 \text { semânticos; } \\
1 \text { identidade } \\
1 \text { contexto. }\end{array}$ & $\begin{array}{l}1 \text { temporal; } \\
1 \text { espaciais; } \\
2 \text { administrativos; } \\
1 \text { técnico; } \\
2 \text { semânticos; } \\
3 \text { descritivos; } \\
2 \text { genéricos. }\end{array}$ & $\begin{array}{l}2 \text { temporal; } \\
1 \text { espaciais; } \\
3 \text { administrativos; } \\
3 \text { semânticos; } \\
3 \text { descritivos; } \\
3 \text { genérico; } \\
2 \text { contexto. }\end{array}$ & $\begin{array}{l}1 \text { temporal; } \\
2 \text { espaciais; } \\
4 \text { administrativos; } \\
4 \text { descritivos; } \\
2 \text { contexto; } \\
1 \text { semântico. }\end{array}$ \\
\hline
\end{tabular}

Investigador 1: saúde cardiovascular

Investigador 2: bem estar animal

Investigador 3: smart cities

Investigador 4: jornalismo de investigação

Investigador 5: biodiversidade

Para classificar as categorias dos termos utilizados pelos investigadores na descrição dos seus documentos fotográficos, usou-se a proposta feita por Jian Qin e Kai Li no seu artigo de 2013 "How Portable Are the Metadata Standards for Scientific Data? A Proposal for a Metadata Infrastructure", tal como pode ser visto na Figura 5. 


\begin{tabular}{|c|c|}
\hline Category & Scope of the category \\
\hline Administrative & $\begin{array}{l}\text { - Meta-metadata, i.e., information about metadata record, standard used, responsible party, rights for } \\
\text { the metadata record, etc. } \\
\text { - Information about data archive/repository. }\end{array}$ \\
\hline Context & $\begin{array}{l}\text { - Information about study/project design, model, and population under study. } \\
\text { - } \quad \text { Aata collection methods, instruments, and constraints. } \\
\text { - Analys methods used. }\end{array}$ \\
\hline Descriptive & $\begin{array}{l}\text { - General attributes about what the resource is and when it is published, released, or made available. } \\
\text { - } \quad \text { Related resources of the resource that is described. }\end{array}$ \\
\hline Geospatial & $\begin{array}{l}\text { Geographic names. } \\
\text { - Geospatial coordinates. } \\
\text { - }\end{array}$ \\
\hline Generic & $\begin{array}{l}\text { - General-purpose elements, including comment, annotation, note, etc. } \\
\text { - Wrapper or nesting elements for structuring and syntactic purposes. }\end{array}$ \\
\hline Identity & $\begin{array}{l}\text { - The name of an entity that is used to identify the entity understood by human users. } \\
\text { - A unique ID either in the form of some code or of a string following an identification system. }\end{array}$ \\
\hline Semantic & $\begin{array}{l}\text { Subject terms describing the content of data. } \\
\text { - Subject or classification categories. } \\
\text { Taxonomic classes. }\end{array}$ \\
\hline Temporal & $\begin{array}{l}\text { - Measurements of time. } \\
\text { - Temporal coverage of the content of data. } \\
\text { - Temporal criteria for data segmentation, processing. }\end{array}$ \\
\hline Technical & $\begin{array}{l}\text { - Parameters, models, measurements used in the dataset. } \\
\text { - Software-, system-, and format-related attributes. }\end{array}$ \\
\hline
\end{tabular}

Figura 5. Description of the category scope Fonte: Qin and Li (2013)

Depois de realizada a descrição foi notório que os investigadores dão especial interesse a termos de descrição de caráter temporal, espacial e administrativo, uma vez que estão presentes nas vinte descrições realizadas. Além disso é importante referir que as restantes categorias surgiram variadas vezes, o que evidencia uma descrição vasta e representativa.

As descrições, por norma, ultrapassaram sempre a marca de dez descritores o que não é, de maneira nenhuma, um número redutor quando se fala de descrição. É evidente uma preocupação por parte dos investigadores em dar contexto às suas fotografias. Estes podiam limitar-se a um baixo número de termos de descrição, apenas aqueles que mostrassem a cobertura espacial e temporal e a dimensão administrativa envolvida. Contudo, preocuparamse em atribuir termos que permitissem perceber, por exemplo, as bases semânticas e contextuais das fotografias, bem como, as informações de caráter mais técnico.

Esta tarefa, além de mostrar a importância do tratamento da informação fotográfica, nomeadamente da descrição como contributo para a valorização e compreensão dos documentos fotográficos, relata como a componente humana é indispensável no processo de tratamento da informação. É inegável que as ferramentas automáticas podem ser um contributo importante nos sistemas de informação que querem garantir uma gestão de informação eficiente. No entanto, os investigadores que se apoiam em exclusivo na automatização poderão não conseguir ver validadas as ações realizadas, não existirá uma verificação do erro e correção deste e, consequentemente, a interpretação e recuperação dos 
dados podem ficar comprometidas. Com a possibilidade de incorporar a componente humana no processo, a confiabilidade dos resultados é garantida.

Como acréscimo a este facto referir a importância da flexibilidade das tarefas de tratamento da informação. Não deve existir um standard para descrever qualquer que seja o recurso. Devem sim existir diretrizes a seguir e que permitam orientar nas mais diversas tarefas, para que não se verifiquem caminhos dúbios e regras indevidamente instauradas.

Tratar a informação é essencial para assegurar a gestão eficaz e normalizada dos vários documentos tratados, sejam eles de caráter imagético ou textual. A informação percorre diversos caminhos e transita por diversas fases até que seja devidamente gerida. $\mathrm{O}$ ciclo de vida da informação é extremamente complexo, mas altamente intuitivo. Negar este ciclo é negar a importância do processo documental na abordagem natural da gestão de informação nos diversos sistemas. Não existe propriamente uma sequência fixa e estanque para que o ciclo da informação se processe, mas sim um conjunto de necessidades que devem ser cumpridas e que, acima de tudo, devem-se correlacionar, pois só dessa forma a gênese da informação consegue ser devidamente descrita, corretamente organizada, a recuperação fomentada e a comunicação favorecida.

\section{CONCLUSÕES}

Nunca a imagem se impôs de tal forma como atualmente constatamos. O surgimento de alternativas tecnológicas que facilitam a captura da imagem potenciou um salto avassalador na produção de documentos fotográficos que, atualmente, são muito mais que uma recordação de um momento, são a prova de um acontecimento, são um mecanismo que permite passar uma mensagem ao outro, com a corroboração de uma realidade.

A sociedade de informação tende a estreitar relacionamentos, o que desencadeia a sua transformação e novas interações mutáveis entre as pessoas e a informação. Analisando criticamente a sociedade de informação verificamos que esta tem propensão a alicerçar-se em cinco bases distintas, nomeadamente espacial, cultural, política, económica e tecnológica. É sobre este pressuposto que o documento fotográfico se posiciona nesta sociedade como um objeto altamente social e de comunicação que, com todas as características e potencialidades a si agregadas, é um excelente condutor de informação e gerador de conhecimento.

Dúvidas existissem sobre como o documento fotográfico adquire um lugar de destaque na sociedade de informação foram extintas pela necessidade quase sôfrega de capturar um momento através de um dispositivo móvel e imediatamente partilhá-lo com outros, ou mesmo pela vontade de comprovar um acontecimento com a busca ávida de imagens que permitam uma melhor contextualização, interpretação e sensação de pertença ao momento retratado. 
A Ciência da Informação, como ciência social que é, tem um papel importantíssimo, quer no esmiuçamento das questões relacionadas com o documento fotográfico, quer na proposta de soluções que permitam um tratamento de informação devidamente proveitoso para esta tipologia documental. A CI permite que sejam entendidas novas abordagem ao estudo da imagem e, mais do que isso, é capaz de oferecer soluções dignas e uniformes para que os processos que envolvem a gestão de informação sejam equilibrados e vistos como iguais, quer falemos de um documento de caráter textual, quer falemos de um documento de caráter imagético, visto que, embora tenham linguagens distintas, são ambos capazes de serem lógicos, de transmitirem uma mensagem e de fomentarem a interpretação.

\section{REFERÊNCIAS}

BARTHES, Roland. A câmara clara. Lisboa: Edições 70, 2012

BOCCATO, Vera Regina Casari; FUJITA, Mariângela Spotti Lopes. Discutindo a análise documental de fotografias: uma síntese bibliográfica. Cadernos de Biblioteconomia, Arquivística e Documentação 2. Brasil: 84-100, 2006

CZERWINSKI, M.; HORVITZ, E. An investigation of memory for daily computing events. Proceedings of HCI 2002 16th British HCI Group Annual Conference, London: 2231,2002

ELSWEILER, D.; RUTHVEN, I.; JONES, C. Dealing with Fragmented Recollection of Context in Information Management. Department of Computer and Information Sciences, University of Strathclyde. Glasgow: 41-55, 2005

JORNAL DE NOTÍCIAS. Local. [Em linha]. [Consult 2 fevereiro 2018] Disponível em: https://www.jn.pt/local/noticias/aveiro/ovar/interior/baleia-morta-da-a-costa-no-furadouro$\underline{8617520 . h t m l}$

KEENE, Martin. Fotojornalismo: Guia Profissional. Lisboa: Dinalivro, 2002

LACERDA, Aline Lopes de. A fotografia nos arquivos: produção e sentido de documentos visuais. História, Ciências, Saúde 19 (1): 283-302, 2012

PPGCINF- PROGRAMA DE PÓS-GRADUAÇÃO EM CIÊNCIA DA INFORMAÇÃO. $7^{\circ}$ WICI - Workshop Internacional em Ciência da Informação. [Em linha]. [Consult 2 fevereiro 2018] Disponível em: http://ppgcinf.blogspot.pt/p/informacoes-sobre-organizacao.html

QIN, Jian; LI, Kai. How Portable Are the Metadata Standards for Scientific Data? A Proposal for a Metadata Infrastructure. Proceedings of International Conference on Dublin Core and Metadata Applications. Lisboa: 27-29, 2013

ROBLEDANO ARILLO, Jesús. Documentación fotográfica en medios de comunicación social. Em Manual de documentación informativa, 183-290. Madrid: Catedra, 2000 
SERÉN, Maria do Carmo. O Documento Fotográfico: Da Mediação Cultural à Mediação Técnica. Revista do CITCEM. Porto: 183-192, 2013

SANTOS, Ana Carolina Lima. A ilustração fotográfica como recurso retórico: um olhar sobre a fotografia no jornalismo de revista. Revista do Programa de Pós-Graduação em Comunicação da Universidade Federal da Paraíba, n. 2. Brasil: Cultura Midiática, 2009

SIMIONATO, Ana Carolina; NETO, Júlio Afonso Sá de Pinho; SANTOS; Plácida Leopoldina Ventura Amorim da Costa. Ciência da Informação, Imagem e Tecnologia. Informação \& Tecnologia. 2(1). Brasil: 53-65, 2018

SILVA, J. R. Fotografia e ciência: a utopia da imagem objetiva e seus usos nas ciências e na medicina. Boletim do Museu Paraense Emílio Goeldi. Ciências Humanas, 9(2), Brasil: 812,2014
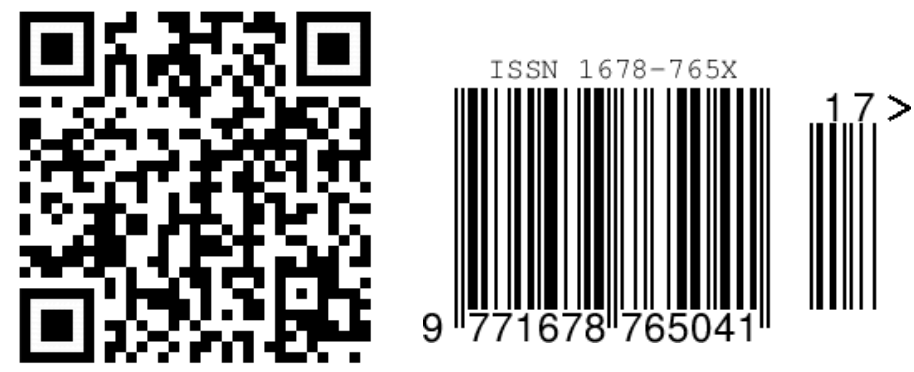